\title{
EDITORIAL
}

\author{
Alberto Ramírez Zuluaga (Q.E.P.D.)
}

\section{EL PROBLEMA DE LA HISTORIA A LA LUZ DE LA TEOLOGIA}

ALBERTO RAMIREZ.

La expresión "teología de la historia" que aparece explícitamente en un inventario de los distintos temas que son objeto de la teología, no significa propiamente que corresponda a la teología establecer una teoría de la historia, en el mismo sentido en que corresponde a otras ciencias. El encuentro actual (1) ha querido incluír una exposición sobre la historia desde el punto de vista teológico. Teniendo en cuenta la afirmación del párrafo anterior, queremos limitar la exposición del tema en el siguiente sentido: en qué sentido han sido afectadas las realidades teológicas por la revolución moderna de la historicidad; en segundo lugar queremos insistir en el hecho de que lo histórico es elemento esencial de la revelación judío-cristiana; una última reflexión sobre la intencionalidad de la historia nos hará comprender el sentido específico que reviste ésta cuando es contemplada en el contexto teológico.

\section{1. - En qué sentido ha influído en las realidades teológicas la afirmación moderna de la historicidad.}

La cultura antigua, expresada por distintos tipos de filosofía (platonismo, aristotelismo, estoicismo), se hizo sentir en la elaboración teológica de la iglesia. Esta cultura antigua tenía, dicho esto a grandes rasgos, una concepción estática del mundo, alimentada por leyes eternas. Es cierto que también aqui había lugar para el movimiento y para las mutaciones. Sin embargo, éstos fueron propiamente considerados como manifestaciones superficiales de algo inmutable, como mutaciones accidentales de una sustancia. El movimiento era mirado como expresión de la finitud y de la desdicha a veces y en este sentido aparecían frecuentemente como castigo y consecuencia de una caída original. La verdad es eterna, la divinidad es un motor inmóvil.

(1) Encuentro sobre historia en la UPB en el mes de Octubre de 1972. 
Basadas en estas categorías, la filosofía y la teología medievales concibieron un orden imponente del ser, figura, a su manera y en distintas medidas, del ser divino inmutable. El fenómeno de la historia y de la mutación histórica no podía ser pasádo por alto, naturalmente, en este proceso. Pero nunca se convirtió explícitamente en un problema de importancia. La historia es un fenómeno que debía ser considerado dentro del ámbito de un orden inmutable.

Para el pensamiento moderno, por el contrario, la historia es precisamente lo contrario: no un momento de este orden inmutable, y este orden es más bien mirado como un momento de la historia, sujeto a ser relativizado por ésta. La realidad no tiene aquí una historia, sino que es precisamente historía. El cambio de situación se presentó propiamente en el S. XIX. En el campo del pensamiento y del arte se realizó esta revolución por el influjo del romanticismo y del idealismo alemán. Para Fichte, por ejemplo, lo absoluto es el hecho que se quiere imponer continuamente y que sin embargo nunca se deja abarcar completamente. Para Hegel, la verdad es movimiento; el espíritu absoluto es el amor, que se aniquila precisamente en la historia y sólo a través de ella vuelve a sí mismo. La historia se convierte así en realización del absoluto. Lo que se afirmó en el idealismo sobre el espíritu absoluto, es afirmado también hoy en el pensamiento existencialista sobre el hombre. El hombre no solamente vive en una historia, que permanece en alguna forma extraña a él, sino que la historia es una dimensión interna del hombre. El hombre es esencialmente el ser peregrino entre el ser y el poder ser, entre el pasado y el futuro. Lo humano es para cada hombre un don; aún más, lo humano es para el hombre una tarea. El hombre es un ser histórico.

Ahora bien, lo que concebía así, en forma abstracta, la filosofía, fue confirmado por las ciencias experimentales en concreto y proyectado hacia el campo de la praxis. La paleontología mostró que el hombre posee una larga pre-historia, dentro de la evolución de toda la naturaleza y de las formas de vida pre-humanas. La etnología y la ciencia histórica mostró que el hombre se transformó desde su primera aparición: la multitud de realizaciones éticas, religiosas, socio-
lógicas, que han sido consideradas como algo natural, en el fondo son realización humana histórica. Existe una evolución regular de la conciencia humana y de la conquista de la dignidad personal del hombre. En fin, aún en el campo eclesial, se afirmó desde mediados del siglo pasado que es posible una evolución de la conciencia dog-
mática del cristianismo.

La afirmación actual tan fuerte de la historicidad se ha hecho sentir en cuestiones teológicas en una forma muy importante: la 
historia de las religiones y la exégesis con sús distintos instrumentos científicos; han reconocido el condicionamiento histórico del mensaje bíblico y la posibilidad de compararlo con otros fenómenos religiosos. Con esto se ha cuestionado en parte la afirmación radical sobre el carácter absoluto de la verdad bíblica: En el ámbito propiamente eclesial se ha dicho que las formäs sociológicas y estructurales, aún más, que las doctrinas correspondientes a estas formas, están condicionadas por el tiempo. Lá iglesia aparece cada día más como una minoría en situación de diáspora. La historia de la salvąción es comparada cualitativamente con la historia profana y somètida a sus mismas leyes. Sobre todo en la teología moral va creciendo más y más la afirmación de la historicidad de la conciencia, en contra, aparentemente, de las afirmaciones estáticas de una ley natural.

Lo anterior nos muestra simplemente que la sensibilidad histórica de nuestros días no ha dejado de ejercer su influjo en el contexto teológico. Pero para poder ofrecer cualquier juicio de valor sobre este influjo, es necesario plantear el problema de lo que significa propiamente en el campo teológico lo que llamamos historia.

\section{2 - La historia como dimensión fundamental del fenómeno religioso judío-cristiano.}

La cuestión del papel jugado por lo histórico en el contexto de un fenómeno religioso concreto, como es el del judaísmo y el del cristianismo, ha sido objeto de gran interés en muchos estudios de nuestros días. Uno de estos estudios que plantean el problema desde la raíz podríamos decir; ha sido el que compara la finalidad religiosa del mito con la de la historia.

Se ha dicho que la historia es la dimensión más primitiva de la fe. Que la revelación del Antiguo y del Nuevo Testamentos se distingue de la de las mitologías propias de las religiones de la naturaleza precisamente por el hecho de ser por esencia una revelación histốrica. Que no eś la natựaleza estática ni las necesidades profundas humanas; lo que constituye el lugar del encuentro con Dios; sino la historia. Que Jesucristo es un momento histórico, que constituye el término de Ia relación dialogal de Dios con el hombre. Con todo esto se ha querido excluír que la revelación cristiana sea una revelación mítica.

Antes de considerar el valor de la afirmación anterior queremos hacer notar el cambio moderno de actitud ante el mito. Hasta el siglo paisado el mito fue mirado en forma peyorativa como una forma in adecuada, aún más, falsa; de expresión leyenda, equivocación. La ac; 
titud moderna frente al mito es otra: el mito es mentalidad y lenguaje existencial, que expresa verdaderamente la totalidad, que sitúa al hombre en un mundo significativo. El mito revela pues también a un hombre en movimiento, pero es necesario mostrar brevemente la estructura del mismo mito, para comprobar mejor la diferencia establecida entre él y la historia.

El hombre aspira a situarse en un mundo con sentido. Sólo por contraposición logra hacerlo. ¿Por contraposición a qué? A la vida ordinaria, que no tiene sentido; a la vida denominada en la fenomenología religiosa, vida profana. Existe un mundo adverso, opaco: es el mundo de todos los días. El espacio y el tiempo, las dos dimensiones de la situación, son profanos, sin sentido. Vivir en este mundo es no haber encontrado la forma de decisión que justifica vivir. Por eso el hombre mítico decide vivir en la situación mítica: en un horizonte no ordinario, ni opaco, sino significativo. Es así como, dentro de una situación sagrada, su decisión crea esa misma situación. La fenomenología de la religión ha establecido con la psicología religiosa las estrategias empleadas por el hombre primitivo para crear su nueva situación: el hombre primitivo abandona el espacio profano, al limitarlo y destruírlo por medic de la elección de determinados lugares, a los cuales acude de tiempo en tiempo, en momentos que también son destrucción del tiempo profano. Es el momento de la fiesta.

Creada esta situación significativa, el hombre encuentra sentido para su propia vida. Los lugares de culto, los templos, los santuarios; los tiempos sagrados para frecuentarlos, las fiestas; indican claramente la forma concreta como se vive esta búsqueda de un mundo significativo, en el cual el hombre encuentra sentido para su vida.

Insistimos en dos elementos fundamentales de esta'mentalidad mítica: por una parte en el hecho del abandono de la situación ordinaria, en búsqueda de una situación nueva, de un compromiso de vida diferente; en segundo lugar, en el hecho de que la acción que debe realizar el hombre, la "historia mítica" si así podemos hablar, es siempre la misma y no puede cambiar, porque sólo la situación arquetípica tiene sentido. Es lo que hace que la acción mítica sea siempre cíclica y consista en un retorno continuo, periódico, hacia una situación primitiva, hacia la creación por ejemplo como momento original.

Miremos ahora lo que ha sido entendido por historia. También aquí miramos el problema bajo los mismos interrogantes planteados a la mentalidad mítica. La historia aparece también como lenguaje: es la manifestación humana, basada en la historicidad del hombre, porque se supone que el hombre es esencialmente un ser en movi- 
miento. La historìa no consiste simplemente en los acontecimientos brutos aislados, sino más bien en la totalidad de los mismos, ligados por una intencionalidad profunda. ¿Cuál es ella? Tal vez es aquí donde pueden apartarse muy fundamentalmente las distintas tesis sobre la historia. Para nuestro caso es fundamental el hecho de que la situación significativa no aparece, dentro del contexto histórico, por contraposición con una situación ordinaria y opaca, como sucedía en el mito. La única situación significativa es la situación ordinaria. El sentido de la vida del hombre no consiste en comprometerse con otro mundo que en el fondo es siempre igual, con una acción arquetípica, en la que entramos a ser protagonistas, sino en emprender en la única situación posible una acción completamente nueva, siempre irrepetible, que tiende irremediablemente hacia el futuro, orientada por una fuerza profunda intencional, que es el hombre mismo. Sobre esta intencionalidad profunda cabe aún una interrogación: ¿a qué motivación obedece, por qué acontece lo que acontece? En este punto se dividen las distintas explicaciones de la historia que llamamos teorías de la historia.

Preguntémonos ahora sobre cómo se presenta dentro de esta perspectiva comparada (mito-historia), el fenómeno concreto que llamamos judaísmo-cristianismo.

Es un hecho universalmente reconocido hoy, en lo que se refiere al mundo judío, que este pueblo estuvo caracterizado por una actitud histórica, no mítica. Podría objetarse que la literatura de los hebreos reviste elementos de cuyo carácter mítico no podría dudarse. Es cierto que la literatura hebrea es más de una vez mitológica, que las limitaciones espacio-temporales realizadas por los judíos revelan un transfondo mítico, que en el culto los israelitas sueñan con situaciones arquetípicas como la del paraíso, la del éxodo, etc. Sin embargo no podemos dejarnos engañar por un lenguaje que no se corresponde totalmente con su contenido. La vida de los judíos es única: su escenario no presenta variaciones sustanciales; la acción humana es siempre irrepetible y está siempre dirigida hacia un futuro, impulsada por una intencionalidad de la cual se puede discutix, pero sin invalidar por eso la orientación escatológica que comunica a la acción misma. En este sentido, Israel es un pueblo histórico, qùe pudo expresarse en parte míticamente.

¿Pero podemos decir otro tanto de la culminación de aquel fenómeno religioso colectivo, en otro fenómeno que llamamos cristianis. mo? Es bien conocido el programa de desmitologización propugnado por un gran conocedor del cristianismo, Rudolf Bultmann. Para encontrar, según él, el cristianismo verdadero, es necesario someterlo a un proceso de desmitologización, porque un acontecimiento histó- 
rico ha sido sometido aquí a una forma mitológica. Lenguaje mitológico y contenido histórico es pues aquí el problema. Bultmann supone pues que la verdad del cristianismo está de parte de lo histórico. Muchos discuten sin embargo los resultados a los cuales ha llegado Bultmann: interpretación existencial del Nuevo Testamento, que tal vez no hace valer en forma suficientemente clara el carácter histórico reconocido. De todos modos, existe también una inșistencia irreversible en que el cristianismo es esencialmente del campo de to histórico y que nunca se insistirá suficientemente sobre el hecho de que los orígenes del mismo son un momento irrepetible y verdaderamente histórico.

No podemos de todas maneras desconocer la objeción hecha a la afirmación anterior por quienes han interpretado posteriormente el cristianismo tal como ha sido vivido, comprendido y expresado en los siglos que siguieron al acontecimiento original. Tal vez se ha juzgado con demasiado rigor al señalar que, la utilización de un instrumento como medio de comprensión y de exprèsión del cristianísmo, instrumento que podemos llamar en general la filosofía helenística, ha llevado a un olvido progresivo de la historia como constituyente esencial del cristianismo: Porque, se dice, la filosofía griega, en cuanto doctrina soteriológica, hace fuerza al cristianismo para que éste convierta su propia doctrina de salvación en un programa que consiste en huír de la historia profana hacia una situación mítica, atemporal o eterna, y aespacial, con la consiguiente negligencia en lo que se refiere al compromiso intratemporal e intramundano.

Pese a todo, esta dimensión histórica de la revelación judía-cristiana, es un constitutivo esencial de la misma y siempre se ha mantenido, aunque a veces como dimensión perdida. Pero aún queremos insistir en el carácter espeć́fico de esta dimensión thistórica en el cristianismo: ¿qué revela la historia, cuando nos situamos en este contexto?; ¿cuál es su intencionalidad más profunda?

\section{3.-La intencionalidad teológica de la historia: la historia como historia de la salvación}

Tradicionalmente se ha distinguido entre historia profana e historia de la salvación y por historia de la salvación se ha entendido la historia judío-cristiana y la historia eclesial. ¿Pero qué las distingue propiamente a estas dos historias? ¿Cómo explicar que unos mismos hombres vivan dos tipos de historias diferentes?

Si miramos la historia de la salvación de Israel, aparece claro que lo que así designamos no es otra cosa que la misma historia profana. Basta con mirar, por ejemplo, los grandes acontecimientos de 
esta historia, los cuales son explicables aún a partir de otras motivaciones, las cuales podrían aún concordar perfectamente con las que tiene en cuenta otra ciencia histórica, aún con teorías históricas que pretenden convertirse en modelo único e integral de interpretación, como el materialismo histórico. Sin embargo, esos acontecimientos son llamados por los israelitas intervenciones de Dios y no son simplemente sumados aisladamente, sino conectados los unos con los otros en forma lineal y entrelazados por una misma intención orientadora: la voluntad salvífica de Dios. ¿Qué puede decir la ciencia de esto? Estamos situados en un plano muy diferente al de la motivación inmediata. En el mismo sentido podríamos hablar del hecho histórico de Jesucristo y de los acontecimientos humanos que hacen la historia con el nombre de Iglesia.

Ya hemos dicho que los hombres que hacen la historia son los mismos que hacen la historia de la salvación. La distinción historiahistoria de la salvación insiste en que el comportamiento humano aceptable, que hace una historia deseable, que conduce al futuro ideal, utópico, y lo hace posible, es el que, en alguna forma, afirma el carácter primero del otro hombre que no soy yo y en consecuencia el carácter secundario de cada sujeto en cuanto "yo". Esto concretamente en la praxis. Esto, sin embargo, no es una fórmula sociológica, sino más bien ética, o en otros términos, religiosa. 